lopment of low-risk low birth weight preterm born infants: Neurodevelopmental aspects from childhood to late adolescence. Early Hum Dev. 2009;85:409-13.

16. Moster D, Lie R, Markestad T. Long-Term Medical and Social Consequences of Preterm Birth. N Engl J Med. 2008;359(3):262-73. 17. Janson H, Squires J. Parent-completed developmental scree- ning in a Norwegian population sample: a comparison with US normative data. Act Paediatr. 2004 Nov;93(11):1525-9.

18. Huddy CL, Bennett CC, Hardy P, Field D, Elbourne D, Grieve R, e.a. Educational and behavioural problems in babies of 32-35 weeks gestation. Arch Dis Child Fetal Neonatal Ed. 2001; 85(1):F23-8.

\title{
Optimale medische begeleiding van kinderen met downsyndroom
}

Een kind met downsyndroom (DS) heeft specifieke uiterlijke kenmerken en lichamelijke afwijkingen, die veroorzaakt worden door trisomie van (een deel van) chromosoom 21. Kinderen met DS hebben specifieke medische zorg nodig, zoals beschreven in de richtlijn 'Medische begeleiding van kinderen met Downsyndroom', die in 2011 geheel is herzien. Aandachtspunten in de zorg voor een pasgeborene met DS zijn: het stellen van de diagnose DS en het meedelen daarvan aan ouders, het geven van actuele en realistische informatie en het starten van de zorg in de eerste weken. Na het eerste levensjaar is het belangrijk dat de (para)medische zorg gecontinueerd wordt en het kind de juiste begeleiding krijgt. De medische zorg is gericht op de algemene gezondheid en op de specifieke bijkomende aandoeningen die bij DS vaak voorkomen. De kinderarts is de zorgcoördinator. De jeugdgezondheidszorg (JGZ) levert een belangrijke bijdrage aan de sociaal-medische zorg voor de kinderen met DS.

Dit artikel is licht gewijzigd ten opzichte van de eerdere publicatie ervan in Praktische Pediatrie (2011;4:220-5).

\author{
Inleiding \\ Kinderen met downsyndroom (DS) hebben extra medi- \\ sche zorg nodig. In binnen- en buitenland zijn voor deze \\ specifieke zorg richtlijnen ontwikkeld. In 2011 is een \\ geheel herziene versie verschenen van de Nederlandse \\ richtlijn 'Medische begeleiding van kinderen met Down- \\ syndroom', ontwikkeld door de werkgroep DS van de \\ Sectie Erfelijke en Aangeboren Aandoeningen (SEAA) \\ van de Nederlandse Vereniging voor Kindergeneeskun- \\ de (NVK). ${ }^{1}$ Deze werkgroep, onder leiding van TNO, \\ bestond uit kinderartsen en vertegenwoordigers van \\ Artsen Jeugdgezondheidszorg Nederland (AJN), Neder- \\ landse Vereniging van Artsen voor Verstandelijk Gehan- \\ dicapten (NVAVG), MEE en Stichting Downsyndroom \\ (patiëntenvereniging). \\ De richtlijn heeft tot doel handvatten te bieden voor een \\ optimale (para)medische begeleiding door de kinderarts \\ en andere betrokken hulpverleners. Kinderen met DS
}

\begin{abstract}
hebben specifieke ondersteuning en begeleiding nodig voor het bereiken van optimale groei en ontwikkeling in een zo goed mogelijke gezondheid.

DS is de meest herkende chromosomale aandoening. Alle kenmerken bij DS worden veroorzaakt door trisomie (van een deel) van chromosoom 21. Jaarlijks worden in Nederland ongeveer 250 baby's met DS levend geboren. ${ }^{2}$ Kinderen met DS hebben een verstandelijke beperking en een vertraagde algemene ontwikkeling, zowel cognitief als motorisch. Ze hebben bijkomende aandoeningen, zoals aangeboren hartafwijkingen, keel-, neus- en oorproblemen, en voedingsproblemen. Bij ieder kind met DS kunnen weer andere aandoeningen op de voorgrond staan die de gezondheid bepalen. In dit artikel wordt een aantal aspecten uit de richtlijn 'Medische begeleiding van kinderen met Downsyndroom' beschreven. Voor de complete informatie en de wetenschappelijke onderbouwing verwijzen we naar de
\end{abstract}


richtlijn, die beschikbaar is via de NVK of is op te vragen bij de auteurs. Daarnaast bevat dit artikel een toelichting op de zorg die de JGZ kan verlenen.

\section{De diagnose}

DS wordt meestal vermoed op grond van uiterlijke kenmerken die typisch zijn voor het syndroom. Belangrijk is te beseffen dat niet één kenmerk specifiek is voor DS, maar dat er meerdere kenmerken aanwezig moeten zijn om de diagnose te vermoeden. Bij neonaten zijn de meest opvallende kenmerken: scheefstand van de ogen naar lateraal boven, epicanthus, lage neusbrug, kleine oren en/ of afwijkende stand van de oren, huidplooi in de nek en hypotonie.

De diagnose wordt gesteld op grond van chromosomenonderzoek bij een klinisch-genetisch centrum. In 95\% van de gevallen betreft DS reguliere trisomie 21, waarbij de herhalingskans bij een volgende zwangerschap ongeveer $1 \%$ is (hierbij moet het risico van de moeder, passend bij haar leeftijd, worden opgeteld). In ongeveer $5 \%$ van de gevallen is er sprake van een translocatie of gonadaal mozaïcisme, waarbij de herhalingskans afhankelijk is van het type afwijking (varieert van 1-100\%). De manier waarop (het vermoeden van) de diagnose DS wordt verteld, heeft veel invloed op ouders. Het is belangrijk dat dit zo zorgvuldig mogelijk gebeurt. ${ }^{3}$ Hierbij is een aantal aandachtspunten van belang. Als men vermoedt dat het kind DS heeft, dient een kinderarts, zo gauw de moeder daartoe in staat is, beide ouders tegelijkertijd te informeren. Idealiter voeren de verloskundige/ gynaecoloog en kinderarts het gesprek met de ouders samen, in aanwezigheid van het kind met DS en op een plek met voldoende privacy.

Het advies is: begin het gesprek op een positieve manier, bijvoorbeeld door de ouders te feliciteren met de geboorte van hun zoon/dochter, en vermijd sombere of negatieve woorden zoals 'slecht nieuws'. Wees ervan bewust dat de ouders zich in een storm van tegenstrijdige emoties bevinden, blij dat hun kind geboren is en ook bedroefd dat hun kind 'anders' is.

In de eerste gesprekken met de kinderarts worden de ouders uitvoerig voorgelicht over de volgende aspecten van DS:

- actuele informatie over wat DS is, waardoor DS wordt veroorzaakt en wat het in de praktijk voor het gezin kan betekenen;

- gebalanceerde, realistische en actuele informatie over de mogelijkheden van mensen met DS in de huidige maatschappij, en verwijzing naar goede bronnen voor meer informatie;

- medische informatie, die beperkt moet blijven tot wat relevant is voor de eerste periode;

- contactinformatie van de Stichting Downsyndroom en/of de mogelijkheid om contact te leggen met andere ouders van een kind met DS.
Actuele en realistische informatie, waarin ook positieve aspecten van DS naar voren komen en waarbij ook praktische adviezen gegeven worden, is belangrijk, omdat het een goede start bevordert en ouders tot steun is. Belangrijk is aan te geven dat, net als bij ieder ander kind, het niet te voorspellen is hoe het leven van een kind met DS er uit zal zien. Wel kan een beeld worden gegeven van de ontwikkelingsmogelijkheden van kinderen met DS in het algemeen. Kinderen met DS hebben een tragere ontwikkeling (zowel cognitief als motorisch), waarbij er tussen de kinderen een grote spreiding in functioneren is. Door goede medische en opvoedkundige begeleiding, stimulering van de ontwikkeling en adequaat onderwijs kunnen de mogelijkheden van ieder kind met DS optimaal worden benut.

Het is niet goed mogelijk om de ouders een exact beeld te geven van de ontwikkelingsmogelijkheden van kinderen met DS. Het bepalen van een intelligentiequotiënt (IO) is bij deze kinderen beperkt betrouwbaar. Bovendien geeft een IQ niet aan welke dagelijkse en schoolse vaardigheden bereikt kunnen worden: er is een grote variatie in wat kinderen met hetzelfde IO kunnen presteren. Als een kind eenmaal de schoolleeftijd heeft bereikt, is voor de aanvraag van leerlinggebonden financiering een IQ-test tegenwoordig niet noodzakelijk. Een verklaring van de kinderarts volstaat. ${ }^{4}$ Mogelijk wordt de wetgeving rond passend onderwijs gewijzigd. Het is nog niet duidelijk wat dit voor de praktijk zal betekenen. Recent onderzoek in een Nederlands cohort kinderen met DS heeft aangetoond dat deze kinderen bij een kalenderleeftijd van 8,1 jaar een gemiddelde ontwikkelingsleeftijd hebben van 3,9 jaar. Hierbij werd een grote spreiding gezien: ongeveer $20 \%$ had een ontwikkelingsleeftijd jonger dan 3 jaar, ruim 70\% scoorde een ontwikkelingsleeftijd van 3 of 4 jaar en bijna $10 \%$ een ontwikkelingsleeftijd van 5 of 6 jaar. ${ }^{5}$ Hoe de vaardigheden op sociaal gebied en de zelfredzaamheid op jongvolwassen leeftijd zijn, is niet te voorspellen. Wel kunnen voorbeelden worden gegeven, zoals: $20 \%$ kan een simpele warme maaltijd bereiden, $20 \%$ kan zelfstandig met het openbaar vervoer reizen, 30\% kan klokkijken, 60\% kan een noodtelefoontje plegen, $65 \%$ kan zich zonder hulp aankleden, $80 \%$ volgt simpele instructies op en $90 \%$ van de jongvolwassenen heeft redelijke tafelmanieren.

\section{De eerste weken}

$\mathrm{Na}$ de eerste gesprekken komt direct de vraag naar voren hoe het nu verder moet. Ouders hebben behoefte aan zorg en aandacht voor het gehele gezin, en aan praktische begeleiding in de dagelijkse zorg. In de eerste periode in het ziekenhuis en thuis is het van belang te zorgen voor continuïteit van zorg, bijvoorbeeld door het aanstellen van een vaste verpleegkundige voor de eerste begeleiding. Ook kan hulp worden geboden bij het zoeken van andere noodzakelijke hulpverleners die ervaring hebben met DS en bij het leggen van contact met andere ouders 
van een kind met DS of ouderverenigingen voor DS. Van de kinderen met DS wordt na de geboorte $86 \%$ in het ziekenhuis opgenomen; meestal voor een paar dagen. ${ }^{6}$ In de eerste weken wordt de zorg gestart. De kinderarts is de centrale hulpverlener voor ouders die recent een kind met DS hebben gekregen. De kinderarts stelt de diagnose en start de juiste zorg. Een van de eerste medische aandachtspunten is of het kind een ernstige hartafwijking heeft of niet. Bij een ernstige hartafwijking wordt het kind het eerste jaar frequent door een kindercardioloog gezien. Indien er geen ernstige hartafwijking is, zullen de ouders voornamelijk contact hebben met de algemeen kinderarts over de begeleiding van onder meer de groei, ontwikkeling, voeding en schildklierfunctie. Een belangrijke taak van de kinderarts is ook om bij ouders de behoefte aan begeleiding in kaart te brengen en te verwijzen naar de juiste (para)medische zorg. De JGZ is, net als bij alle kinderen, vanaf de eerste weken betrokken bij de pasgeborene en de ouders tijdens de reguliere contactmomenten. De neonatale gehoorscreening en de hielprik worden door de JGZ afgenomen tussen de vierde en zevende dag na de geboorte (tenzij het kind in het ziekenhuis is opgenomen). In de tweede levensweek gaat de jeugdverpleegkundige op huisbezoek en op de leeftijd van 4 weken worden het kind en de ouders door de jeugdarts gezien. De JGZ heeft bij kinderen met DS de taak om de zorg te bieden die alle kinderen en ouders nodig hebben, zoals aandacht voor vragen van ouders over voeding, slaap, huilen en de relatie tussen het kind en de andere kinderen in het gezin. Voor het monitoren van de groei wordt het specifieke groeidiagram voor kinderen met DS gebruikt (indien aanwezig in het DDJGZ kan dit digitaal worden bijgehouden). Primaire preventie en vroegsignalering is ook bij kinderen met DS een belangrijke taak van de JGZ, bijvoorbeeld het geven van vaccinaties, advisering over vitaminesuppletie en veiligheid en screening op dysplastische heupontwikkeling en visusstoornissen. De JGZ kan aan gezinnen met een kind met DS belangrijke zorg bieden, vanwege haar specifieke expertise, onder meer op het gebied van het inschatten van de behoefte van ouders aan hulp, het geven van voorlichting en het bieden van begeleiding bij opvoedingsproblemen en zindelijkheidsproblematiek.

De JGZ is ingebed in de Centra voor Jeugd en Gezin (CJG). Voor ouders is het belangrijk te weten dat zij via deze centra extra zorg kunnen krijgen, zoals praktische hulp van een lokale $M E E$. De CJGs zijn laagdrempelige voorzieningen in de wijk met een variabel aanbod (MEE, bureau jeugdzorg, verloskundigen, maatschappelijk werk, diëtisten, logopedisten, enz.). Het CJG werkt nauw samen met onderwijs (zorgadviesteams) en voor- en naschoolse voorzieningen (peuterspeelzaal, kinderdagverblijf en naschoolse opvang).

Het is wenselijk kinderfysiotherapie vroeg (in ieder geval in het eerste levensjaar) te starten, bij voorkeur bij een kinderfysiotherapeut met ervaring met DS. Het doel van fysiotherapie is de motorische ontwikkeling te volgen en ouders te begeleiden bij het stimuleren en bijsturen van deze ontwikkeling. Kinderen met DS hebben een specifiek ontwikkelingsprofiel. De motorische ontwikkeling verloopt trager en anders dan bij kinderen zonder DS. Op de voorgrond staan problemen met houdingscontrole en balans. De kinderfysiotherapeut kan ouders vanaf de geboorte van het kind adviezen geven hoe zij het beste kunnen omgaan met de hypotonie en hypermobiliteit. Vroege logopedische begeleiding voor kinderen met DS, beginnend in het eerste levensjaar, is van belang om de mondmotoriek optimaal te ontwikkelen, eetproblemen te voorkomen en de spraak- en taalontwikkeling te stimuleren. Voldoende kennis over specifieke problemen in de verschillende fasen van het eet- en drinkproces is daarbij essentieel. Zo veroorzaken de afwijkende bewegingen van de tong en de hypotonie van de lip- en wangspieren problemen met het drinken en kauwen. Hoewel er geen wetenschappelijk bewijs is voor het effect van logopedische begeleiding wordt deze door experts wel geadviseerd.

Borstvoeding verdient ook bij kinderen met DS de voorkeur, niet alleen om emotionele redenen of de voordelen van de immuniteitsopbouw, maar ook omdat het de mondmotoriek stimuleert.

Vanaf de eerste levensmaanden kan men Early Intervention toepassen. Hiermee bedoelt men (meestal) een gerichte opvoeding en een intensieve ondersteuning van de ontwikkeling door een actieve houding van de ouders, ondersteund door een programma en bij voorkeur met gespecialiseerde hulpverleners. Early Intervention is in 1988 in Nederland geïntroduceerd door de Stichting Downsyndroom (SDS), aanvankelijk in de vorm van het in Australië ontwikkelde Macquarie-programma, later als het hiervan afgeleide programma Kleine Stapjes. Dit programma en enkele voorlichtingsfilms hierover zijn bij de Stichting Downsyndroom te bestellen (via www.downsyndroom.nl). Er is enige evidentie voor het positieve effect op korte termijn van Early Intervention. ${ }^{7}$ Binnen de ontwikkelingspsychologie wordt aangenomen dat Early Intervention de vroege ontwikkeling weinig verbetert (echter er is geen onderzoek dat het nut bevestigt of ontkracht). Wel geeft Early Intervention de ouders meer mogelijkheden om hun kind in zijn ontwikkeling te ondersteunen.

Een aantal aangeboren afwijkingen, die vaak voorkomen bij DS, kan in de eerste weken medische problemen bij kinderen met DS veroorzaken:

Aangeboren hartafwijkingen komen bij 43-58\% van de kinderen met DS voor. Een atrioventriculairseptumdefect (AVSD) is de meest voorkomende afwijking (in de helft van de gevallen), naast het ventrikelseptumdefect (VSD) (bij een derde van de gevallen). Aangeboren hartafwijkingen bij DS kunnen ook asymptomatisch verlo- 
pen (ook zonder hartruis), zelfs als er al pulmonale hypertensie is ontstaan. Daarom wordt bij alle kinderen met DS echocardiografisch onderzoek in de eerste maand na de geboorte uitgevoerd.

Aangeboren maag- en darmafwijkingen zijn bij 4-10\% aanwezig, vooral oesofagusatresie/tracheo-oesofageale fistels, pylorusstenose, duodenumstenose/web/atresie, de ziekte van Hirschsprung en anusstenose/atresie. Deze aandoeningen presenteren zich met buikklachten zoals braken en een opgezette buik.

Bij 5-10\% van de neonaten met DS komt preleukemie voor, ook wel aangeduid als leukemoïde reactie, transiënte leukemie (TL) of myeloproliferatief syndroom. Hoewel dit in de regel spontaan verdwijnt, kunnen ook ernstige symptomen ontstaan waarvoor behandeling nodig is. Bij $20 \%$ van de kinderen met een preleukemie ontstaat later alsnog een echte myeloïde leukemie (gemiddeld na 20 maanden). ${ }^{8}$ Voor meer informatie over preleukemie bij DS, zie www.skion.nl/voorartsen. Congenitale hypothyreoïdie komt bij pasgeborenen met DS vaker voor dan bij pasgeborenen zonder DS (9,2-35,2 per 1000 vs. 0,56 per 1000). Met de hielprik wordt hierop gescreend.

Oogafwijkingen komen vaker voor bij kinderen met DS. Congenitaal cataract komt voor bij 1-13\% van de kinderen met DS. Geadviseerd wordt elk kind met DS voor de derde levensmaand door de oogarts te laten onderzoeken op cataract. Nystagmus wordt bij 6-33\% van de mensen met DS gezien en is meestal aangeboren. Nystagmus is niet te genezen, maar kan verminderen met het toenemen van de leeftijd, of door het corrigeren van een eventuele refractieafwijking. Daarom is het belangrijk kinderen met een nystagmus naar de orthoptist of oogarts te verwijzen. Opsporing van visuele stoornissen door de JGZ vindt plaats volgens de JGZ-richtlijn 'Opsporing visuele stoornissen o-19 jaar'. Voor de oudere kinderen bij wie screening met de Landolt-C Ringen (LR)-kaarten niet lukt, kan de Lea Hyvärinen (LH) kaart en het LH Crowded Book worden gebruikt. Verwijzing naar de oogarts, indien het kind daar al niet onder controle is, kan rechtstreeks met berichtgeving aan de huisarts. ${ }^{9}$

\section{Nieuw in de richtlijn}

De medische begeleiding van kinderen met DS is gericht op de algemene gezondheid en op specifieke bijkomende aandoeningen die bij DS vaak voorkomen. Ten opzichte van de vorige Nederlandse richtlijn (uit 1998) zijn de meeste onderwerpen uitgebreid en is een aantal onderwerpen toegevoegd. Ook zijn nieuwe groeidiagrammen voor kinderen met DS samengesteld; de diagrammen zijn te downloaden via www.tno.nl/groei. Bij het samenstellen van deze groeidiagrammen zijn alleen gezonde kinderen met DS geselecteerd, dus geen kinderen met aandoeningen die de groei kunnen beïnvloeden (zoals een ernstige hartafwijking, hypothyreoïdie, coeliakie, een aangeboren maag-darmafwijking of een afwijking aan het bewegingsapparaat) of kinderen die medicatie gebruiken die de groei kan beïnvloeden (zoals corticosteroïden of anti-epileptica). ${ }^{10}$

Omdat de referentiediagrammen op deze 'gezonde' groep zijn gebaseerd, geven ze goed weer wat de optimale groei van een kind met DS is. De gemiddelde eindlengte van jongens met DS is 163,4 cm en van meisjes met DS 151,8 cm (ter vergelijking: in de algemene populatie is de eindlengte van jongens $183,8 \mathrm{~cm}$ en van meisjes 170,7 cm). Voor kinderen met DS zijn er ook aparte target height formules gemaakt, waarbij rekening is gehouden met de kortere eindlengte die de kinderen bereiken. De formules zijn:

- target height jongen met DS $=41,8+0,328$ * lengte vader $(\mathrm{cm})+0,359^{*}$ lengte moeder $(\mathrm{cm})$;

- target height meisje met DS $=8,64+0,387^{*}$ lengte vader $(\mathrm{cm})+0,422{ }^{*}$ lengte moeder $(\mathrm{cm})$.

De eindlengte bij een jongen met DS mag variëren van $10 \mathrm{~cm}$ onder tot $10 \mathrm{~cm}$ boven deze berekende target height, en bij een meisje met DS van $12 \mathrm{~cm}$ onder tot 12 $\mathrm{cm}$ boven de berekende target height.

Ook het gewicht van kinderen met DS is in kaart gebracht. Kinderen met DS hebben twee keer zo vaak overgewicht of obesitas als kinderen in de algemene Nederlandse populatie. Al vanaf de leeftijd van 4 jaar heeft meer dan $25 \%$ van de jongens en $30 \%$ van de meisjes met DS overgewicht of obesitas.

\section{Standaardzorg}

Geadviseerd wordt de zorg voor kinderen met DS in gecoördineerd verband aan te bieden, bij voorkeur in een multidisciplinair team. De kinderarts is hierbij de zorgcoördinator. In Nederland zijn speciaal voor kinderen met DS ruim 20 zogeheten Downteams of Downpoli's opgericht. Dit zijn multidisciplinaire teams, die de zorg voor de kinderen coördineren. Een lijst van alle Downteams in Nederland is te vinden op de website van Stichting Downsyndroom (www.downsyndroom. $\mathrm{nl}$ ). Het hoofddoel van de teams is, door het in multidisciplinair verband aanbieden van medische en paramedische deskundigheid, de lichamelijke conditie van kinderen met DS te verbeteren en daarmee de voorwaarden te scheppen voor een optimale ontwikkeling. Belangrijk daarbij is de teambespreking die aansluitend aan het bezoek van het kind aan het team plaatsvindt. In de teambespreking vindt integratie van de onderzoeksresultaten plaats. Vervolgens wordt de advisering afgestemd op de mogelijkheden van het kind en de ouders. De andere zorgverleners die bij het kind met DS zijn betrokken (op medisch, educatief en sociaal gebied) worden van de bevindingen op de hoogte gesteld. Tabel 1 en 2 tonen de minimaal aanbevolen contactmomenten bij de verschillende professionals en de minimaal aanbevolen screeningen. Via een Downteam kan veel van deze standaardzorg op 1 of 2 ochtenden worden 
Tabel 1 Aanbevolen minimale frequentie van contactmomenten. De contactmomenten op indicatie zijn niet weergegeven.

\begin{tabular}{|c|c|c|c|}
\hline zorgverlener & leeftijd & frequentie & opmerkingen \\
\hline \multirow{3}{*}{$\begin{array}{l}\text { kinderarts } \\
\text { Downteam/poli* }\end{array}$} & 0-18 jaar & 1x per jaar & coördinatie van zorg voor DS \\
\hline & 0-10 jaar & 1x per jaar & \\
\hline & $>10$ jaar & $1 \times$ per 2 jaar & \\
\hline \multirow[t]{2}{*}{ kno-arts } & 0-5 jaar & 1-2x per jaar & inclusief gehoorscreening \\
\hline & $>5$ jaar & 1-2x per 2 jaar & \\
\hline oogarts & 0-2 maanden & eenmalig & \\
\hline \multirow[t]{2}{*}{ orthoptist } & 0-6 jaar & bij 1, 3, 4 en 6 jaar & \\
\hline & $>6$ jaar & iedere 4 à 5 jaar & \\
\hline tandarts & 0-18 jaar & 2x per jaar & bij 6, 9, 12 en 15 jaar röntgendiagnostiek \\
\hline orthodontist & $>6$ jaar & bij 6 jaar & \\
\hline fysiotherapeut & $<1$ jaar & & eerste contact \\
\hline logopedist & $<1$ jaar & & eerste contact \\
\hline JGZ-team & 0-18 jaar & conform JGZ-basistakenpakket & inclusief vaccinaties \\
\hline AVG & $\geq 18$ jaar & & reguliere zorg voor DS \\
\hline
\end{tabular}

* Contact met zorgverleners in gecoördineerd verband, bij voorkeur een multidisciplinair Downteam.

Tabel 2 Minimaal benodigde specifieke screeningstests, aangevraagd door de kinderarts. Standaard screenend (lichamelijk) onderzoek is niet weergegeven.

\begin{tabular}{|c|c|c|c|}
\hline aandoening & leeftijd & frequentie & screening \\
\hline hartafwijking & 0-4 weken & & hartecho \\
\hline schildklierstoornis & $>1$ jaar & 1x per jaar & TSH, vrij T4 \\
\hline \multirow[t]{2}{*}{ coeliakie } & $<2$ jaar & optioneel & HLA-DQ2 en -DQ8 \\
\hline & & $1 x$ per 2 jaar* & IgA en IgA tTgA \\
\hline
\end{tabular}

*Indien HLA-DQ2 of -DQ8 positief of niet verricht is.

geboden. Aanbevolen wordt een bezoek aan een Downteam (of anderszins contact met zorgverleners in gecoördineerd verband) met een minimale frequentie van eenmaal per jaar tot de leeftijd van 10 jaar, en daarna eenmaal per 2 jaar.

Systematische primaire preventie (op individueel en collectief niveau) is een specifieke taak van de JGZ. Ook voor kinderen met DS is de JGZ belangrijk naast het traject in de kindergeneeskunde. Deze twee expertises kunnen er door een goede samenwerking voor zorgen dat ouders en kind zowel op medisch als psychosociaal gebied goede zorg krijgen. Het is belangrijk dat de JGZ weet welke zorg de kinderarts waar het kind onder controle is biedt en welke taken er voor de JGZ zijn. De multidisciplinaire teams omvatten bijvoorbeeld niet allemaal dezelfde disciplines, en bieden de zorg op verschillende leeftijden anders aan. Alleen als de JGZ en de kinderarts goed van elkaars zorg op de hoogte zijn (zowel organisatorisch als inhoudelijk) kan optimale zorg aan de kinderen met DS gegeven worden. In principe is de kinderarts de zorgcoördinator, maar voor individuele patiënten kunnen hierover andere afspraken gemaakt worden. ${ }^{11}$

De JGZ is nauw betrokken bij het (speciaal) onderwijs. Op elke school (primair, speciaal en voortgezet onderwijs) is er een zorgadviesteam. De JGZ is onderdeel van dit multidisciplinaire overleg en meestal de verbinding naar het CJG. De JGZ heeft op school ook voor kinderen met DS een taak bij het vroegtijdig signaleren en opsporen van problemen, evalueren van de zorg voor het kind en zorgdragen voor adequate begeleiding thuis, op school, in de vrijetijdsbesteding en bij toeleiding naar werk en/of dagbesteding. Indien een kind of gezin zorg op maat nodig heeft, kan de JGZ dit bieden. Hierbij wordt voor kinderen op het speciaal onderwijs tot de leeftijd van 9 jaar 1 contactmoment per 2 jaar geadviseerd en zolang ze voortgezet onderwijs volgen 1 contactmoment per 3 jaar. ${ }^{12}$ Bij het bereiken van de volwassen leeftijd vindt er transitie plaats naar een arts voor verstandelijk gehandicapten (AVG-arts).

\section{Conclusie}

De zorg voor kinderen met DS kent een aantal specifieke aandachtspunten. Bij een pasgeborene is dat het meedelen van (het vermoeden van) de diagnose DS, het in kaart brengen van de acute zorg die het kind nodig heeft, waarbij diagnostiek naar een congenitale hartafwijking 
essentieel is, en het starten van de juiste (para)medische zorg (zoals fysiotherapie en logopedie).

Op de kinderleeftijd is de zorg gericht op de algemene gezondheid, met aandacht voor het optimaal functioneren in het gezin en in de maatschappij. Met de nieuwe groeidiagrammen voor kinderen met DS hebben artsen een goed instrument om de algemene gezondheid van het kind te monitoren. Aandacht moet zowel naar lengte als gewicht uitgaan en preventie van overgewicht en obesitas is daarbij een essentieel aandachtspunt. De medische zorg richt zich daarnaast op specifieke bijkomende aandoeningen die bij DS vaak voorkomen. Daarbij moet de arts alert zijn op mogelijk onderliggend lijden in alle orgaansystemen, die in de verschillende hoofdstukken van de richtlijn worden uitgelicht. De JGZ kan een belangrijke rol spelen bij de begeleiding van ouders met betrekking tot verzorging, groei, ontwikkeling, opvoeding en gedrag.

\section{Literatuur}

1. Borstlap R, Gameren-Oosterom HBM van, Lincke C, Weijerman, $M$, Wieringen $H$ van, Wouwe JP van. Een update van de multidisciplinaire richtlijn voor de medische begeleiding van kinderen met Downsyndroom. Utrecht: Nederlandse Vereniging van Kindergeneeskunde; 2011.

2. Mohangoo AD, Gameren-Oosterom HBM van, Schönbeck $Y$, Buitendijk SE, Pal van der-Bruin de KM, e.a. TNO-rapport: Aangeboren afwijkingen in Nederland 1997-2009. Leiden: TNO. TNO/CH 2011.042; 2011.

3. Skotko BG, Capone GT, Kishnani PS. Postnatal diagnosis of Down syndrome: synthesis of the evidence on how best to deliver the news. Pediatrics. 2009;124:e751-8.

4. Aanvragen leerlinggebonden financiering (Wet passend onderwijs): http://www.rijksoverheid.nl/onderwerpen/ passend-onderwijs/vraag-en-antwoord/hoe-vraag-ik-leerlinggebonden-financiering-lgf-aan-voor-mijn-kind.html.

5. Gameren-Oosterom HBM van, Fekkes M, Buitendijk SE, Ashna DM, Bruil J, Wouwe JP van. Development, Problem Behavior,
Quality of Life in a Population Based Sample of Eight-Year-Old Children with Down Syndrome. PLoS ONE 2011;6:e21879. doi:10.1371/journal.pone.0021879.

6. Weijerman ME, Furth M van, Vonk Noordegraaf A, Wouwe JP van, Broers CJM, Gemke RJBJ. Prevalence, neonatal characteristics, and first-year mortality of Down syndrome: a national study. J Pediatr. 2008;152:15-9.

7. Guralnick MJ. Effectiveness of early intervention for vulnerable children: a developmental perspective. Am J Ment Retard. 1998;102:319-45.

8. Massey GV, Zipursky A, Chang MN, Doyle JJ, Nasim S, Taub JW, e.a. A prospective study of the natural history of transient leukemia (TL) in neonates with Down syndrome (DS): Children's Oncology Group (COG) study POG-9481. Blood. 2006; 107:4606-13.

9. Coenen-van Vroonhoven EJC, Lantau VK, Eerdenburg-Keuning IA van, Velzen-Mol HWM van. JGZ-richtlijn Opsporing visuele stoornissen o-19 jaar, eerste herziening. Bilthoven: RIVM/ Centrum Jeugdgezondheid; 2010.

10. Gameren-Oosterom HBM van, Dommelen P van, OudesluysMurphy AM, Buitendijk SE, Buuren S van, Wouwe JP van. Healthy growth in children with Down syndrome. PLoS One 2012;7(2):e31079. doi:10.1371/journal.pone.0031079.

11. Heerwaarden Y van, Bakker B. Concept-handreiking Samenwerking en gegevensoverdracht tussen het ziekenhuis en de jeugdgezondheidszorg; beschrijving randvoorwaarden. Utrecht: Nederlands Centrum voor Jeugdgezondheid; 2012. http://www.ncj.nl/bibliotheek/nieuws/details/669/handreiking-8216-samenwerking-en-gegevensoverdracht-tussen-hetziekenhuis-en-de-jeugdgezondheidszorg-beschrijving-randvoorwaarden-8217-gereed.

12. Willems WAJJ, Nagelsmit WM. Notitie speciale zorg voor speciale kinderen. AJN; 2008.

13. Schonbeck Y, Talma H, Dommelen P van, Bakker B, Buitendijk SE, HiraSing RA, Buuren S van. Increase of prevalence of overweight in Dutch children and adolescents: A comparison of nationwide growth studies in 1980, 1997 and 2009. PLoS ONE 6(11): e27608. doi:10.1371/journal.pone.0027608. 